A historical review of the development of penicillins with particular reference to the antimicrobial spectrum and clinical evaluation of piperacillin.

Keighley MRB, Burdon DW, Arabi Y, et al. Randomised controlled trial of vancomycin for pseudomembranous colitis and postoperative diarrhoea. Br Med f 1978; ii :1667-9.

This study showed that vancomycin was an effective and safe treatment for pseudomembranous colitis.

Ness HC. Current practices in antimicrobial dosing. Rev Infect Dis 1981 ;3: 12-8.

Reviews current practice relating to dosage and duration of antibiotic treatment.

Selwyn S. Mechanisms and range of activity of penicillin and cephalosporins. In: The $\beta$-lactam antibiotics: penicillins and cephalosporins in perspective. London: Hodder and Stoughton, 1980;1-55.
The antibacterial spectrum and mode of action of penicillins and cephalosporins are discussed.

Shaw EJ, Datta N, Jones G, Marr FM, Froud WJB. Effect of stay in hospital and oral chemotherapy on the antibiotic sensitivity of bowel coliforms. f Hygiene 1973;71:529-34.

Reviews the emergence of resistance in bowel coliforms during antibiotic treatment.

Swartz MN. Clinical aspects of legionnaires disease. Ann Intern Med 1979; 90:492-5.

Clinical features of legionnaires disease and its management are discussed.

Wise R, Reaves DS. Advances in therapy with antibacterial folate inhibitors. f Antimicrob Chemother $1979 ; 5$, suppl B.

Reviews the role and development of folate inhibitors.

\section{Clinical curio: perforating eye injury from an unusual cause}

Two young men in two months presented to the eye casualty department of the Leicester Royal Infirmary with perforating eye injuries from the same unusual cause. Both had been struck in the eye by a large fencing staple while they were pulling down nylon netting stapled to wooden posts. Both still have normal visual acuity.

Case 1-A 16 year old boy presented with a fencing staple $2 \mathrm{cms}$ long transfixing his left lower eyelid (fig $1 \mathrm{a}$ ). $X$ ray appearances (figs $1 b, 1 c)$ and clinical examination showed that the globe was perforated by one arm of the staple, the tip of which could be seen with a funduscope in the vitreous compartment. He had little discomfort and the visual acuity in the affected eye was $6 / 36$. The staple was removed

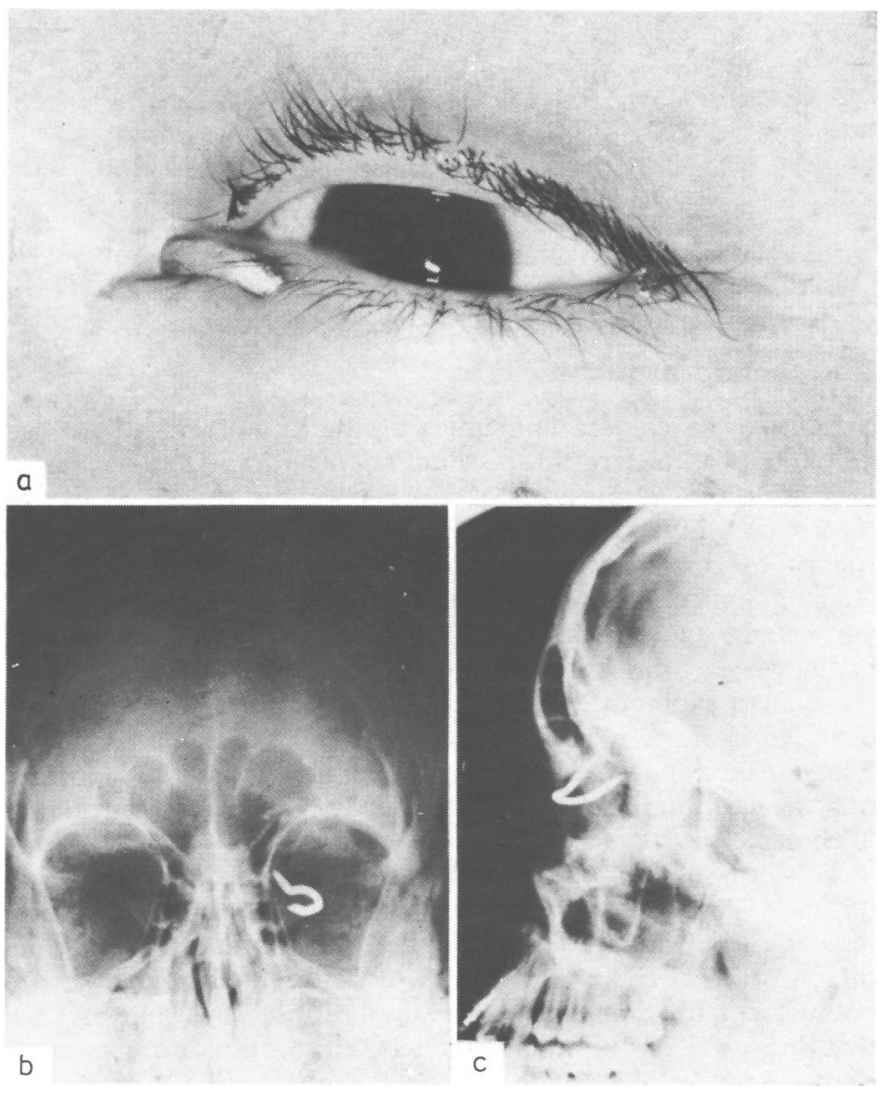

Clinical and $x$ ray appearances of staple injury to the left eye (case 1 ).

under general anaesthesia, requiring quite forceful traction to extract it. The perforation lay $6 \mathrm{~mm}$ posterior to the limbus. The scleral defect was sutured with 5/0 Dacron, and cryotherapy was applied around the wound and behind it. He was given intensive prophylactic local and systemic antibiotics. Seven days later he had regained left visual acuity of $6 / 9$ unaided. Fifteen months later the vision was $6 / 5$, the eye was not inflamed, and the retina was flat.
Case 2-A 21 year old man presented with a painful right eye after being struck by a fencing staple. Examination showed a full thickness puncture wound of the periphery of the right cornea, which was apparently self sealing; the anterior chamber was present but reduced. The iris was adherent to the back of the wound, though there was no prolapse of iris tissue through the wound. The lens was undamaged, and the visual acuity was $6 / 18$ in the affected eye. He was treated conservatively with topical and systemic antibiotics. The corneal wound healed well, and the anterior chamber reformed to normal depth. A small scar remains with iris anterior synaechias. Fourteen months later the visual acuity had returned to $6 / 5$.

No similar cases have been reported. $S m^{1}{ }^{1}$ and Blake ${ }^{2}$ described ocular injuries in agricultural workers, in whom perforating injuries by tools or metal are rare. Johnston ${ }^{3}$ reported a wider range of perforating injuries, but did not give all the causes, although, again, injuries with metal are rare in agricultural workers but prevalent in industrial workers. It is clear, especially in case 1 , that the staple was propelled with considerable force into the eye. The elastic nature of nylon netting presumably produced a catapult effect when the staple came free. Perforating puncture wounds of the eye, even when apparently severe, are compatible with the retention of good vision if promptly and appropriately treated. Perforating injuries where vegetable matter may contaminate the wound are vulnerable to infection, a devastating complication. Both these patients were treated vigorously with antibiotics prophylactically, and neither developed infection. Both were fortunate in the outcome of their injuries from this previously unrecognised hazard.

I should like to thank Miss D Callaghan for the photographic help, Mrs J Wood for her secretarial help, and Mr D B Goulstine and Mr D J Austin for permission to report these cases.-A B BECKINGSALE, ophthalmologist, Leicester.

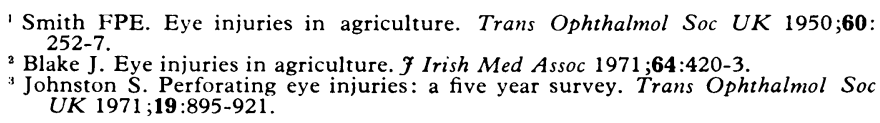

I find that circumcision of adults done under local anaesthesia using a basal ring block of xylocaine without adrenalin is satisfactory, except for some brief discomfort when cutting through the frenulum with scissors. Stitching this area causes few complaints. Can this discomfort be explained on anatomical and physiological grounds and can it be remedied?

The distribution of sensory nerve fibres from the dorsal nelve of the penis is particularly profuse not only to the glans penis but also to the skin of the frenulum. Indeed, this region is characterised by the presence within the papillae of the skin of specialised encapsulated sensory nerve terminals. The most likely explanation for the discomfort on cutting the frenulum relates to this rich innervation and suggests that the dorsal nerves of the penis are only partially blocked at the time of surgery. An indication of the efficiency of the block can be achieved by testing sensation over the surface of the glans. It seems unlikely that other nerves supplying the penis that lie deep to the site of injection could be responsible for persistent sensation of the frenulum. These autonomic cavernous nerves supply the vasculature of erectile tissue and are not considered to carry afferent nerves from the skin of the penis.-JOHN GOSLING, professor of anatomy, Manchester. 